\title{
1. Digitalization through the lens of law and democracy
}

\section{Maurice Adams and Corien Prins}

\section{INTRODUCTION}

The transformative impact of digitalization can scarcely be overestimated. ${ }^{1}$ Effects are visible within the national state and across borders, as well as towards knowledge production and political participation and social structures. ${ }^{2}$ Examples abound. In the so-called 'Arab Spring' online tools enabled broad political and social mobilization in several countries. ${ }^{3}$ Meanwhile, national authorities nonetheless continue to assert influence over, indeed control of, the internet by means of governing bodies, regulations and laws: both China and Turkey have a reputation in this regard. ${ }^{4}$ At the same time, the now regular online - sometimes semirestricted - platforms such as Facebook, LinkedIn, YouTube and Twitter typically serve causes that are thought to be beneficial for democracy: mobilization, encouragement, creativity and engagement. Many governments have indeed taken digital initiatives to share information (for example by publishing policy documents), consult citizens (for instance concerning legislation) and allow them to participate in decision making (through apps, smartphones and tablets). Moreover, what is now commonly referred to as big data, i.e. the smart deployment of data analysis

1 Castells understands digitalization as one of the defining characteristics of the modern era. M Castells, The Rise of the Network Society. The Information Age: Economy, Society, and Culture (2nd edition, with a new Preface, Oxford, Wiley-Blackwell 2009) 5. See also S Brennen and D Kreiss, 'Digitalization and Digitization', in K Bruhn Jensen, RT Craig, JD Pooley and EW Rothenbuhler (eds), The International Encyclopedia of Communication Theory and Philosophy (Oxford, Wiley-Blackwell 2016) <http://culturedigitally.org/2014/09/digitaliza tion-and-digitization/> accessed 28 August 2016.

2 Brennen and Kreis (n 1).

3 Although it is not clear to what extent these tools were also decisive in national 'regime change'.

4 See Chapter 14. 
techniques, is considered a key factor not merely for successful policy formulation, but also for implementation in domains such as safety and security, traffic management, health care and environmental protection. Government, the public sector and politics ${ }^{5}$ are influenced by the power of big data in that it combines hindsight (pattern analytics), insight (real-time analytics) and foresight (predictive analytics).

The aim of this volume is to shed light on some of these processes from the angle of law and democracy. To what extent do forms of digital political engagement change the traditional architectures of participation and democratic decision making? How receptive or responsive are governments and authorities to digital democratic movements? What is the role of government in upholding the values of our democratic society, while at the same time ensuring the flexibility that is needed with regard to private sector innovations? What type of regulatory instruments facilitate digital technologies for democratic purposes, and which ones hinder or even block these purposes? How should we judge these developments in the light of the cross-border effects of digitalization? How, in this context, can lawyers or other actors adapt their analytical toolkits to the realities of a largely fragmented and fluid regulatory landscape? ${ }^{6}$

These are challenging questions, but what makes the topic even more challenging is that even a brief glance at the 'democracy debates' - as they unfold, for example, in popular media as well as in academic circles makes it clear that there is no generally accepted or one-size-fits-all notion of democracy. ${ }^{7}$ One of the main reasons for this might well be that '[w] hen used adjectivally, "democratic" does not signify full realization of

5 The role of Facebook in the 2016 US elections serves as a distinct example. See https://www.wired.com/2016/11/facebook-won-trump-election-not-just-fakenews/ accessed 27 April 2017.

6 P Zumbansen, 'Transnational Comparisons: Theory and Practice of Comparative Law as a Critique of Global Governance', in M Adams and JA Bomhoff (eds), Practice and Theory in Comparative Law (Cambridge, Cambridge University Press 2012) 189-90. Although not the focus of this volume, we should note that the dividing line between public and private sectors is blurred. Illustrative of the growing prominence of the private sector as 'an extension' of public administration is eCall, the EU project that involves fitting cars with electronics that emit an emergency signal in the event of an accident. It was designed by an ad hoc committee of some 144 actors - including the European Commission, national authorities, the car industry, mobile telecommunication operators, private emergency services and insurers. See http://ec.europa.eu/transport/road_safety/spe cialist/knowledge/esave/esafety_measures_unknown_safety_effects/ecall_en.htm accessed 27 April 2017.

7 See also Chapter 8 . An overview of concepts of democracy can be found in D Held, Models of Democracy (Stanford, Stanford University Press 2006). 
some ideal, but a variety of norms and ideals that can be realized . . . under a wide range of conditions' ${ }^{8}$ As a result, this variety is reflected in just as many different conceptions of democracy. This also helps us understand, at least in part, the sometimes heated debate about the nature of democracy: adopting a position in the democracy debate is for many not some accessory issue, like ordering a side dish to go with one's main course. ${ }^{9}$ In this volume the plural nature of democracy takes centre stage, and in Section III of this chapter different conceptions of democracy will be singled out with regard to the different chapters. Based on this, in Section IV we add some further thoughts on the topic and advocate a networked approach. However, we first reflect on what we mean by digitalization and on how its impact or role can be seen or understood (Section II).

But before reaching that discussion, two qualifications must be added. First: an introduction like this is meant to structure the variation of contributions to the volume at hand. At the same time, such a structure also represents the reading experience of the authors of this introduction and cannot do full justice to the variety of viewpoints that can be discerned in most of the chapters themselves. The chapters are, in other words, not necessarily limited to what the heading under which they are classified here suggests; reading this introduction should therefore not substitute for reading the chapters themselves. Second: this volume does not claim to provide a general or unified theory about how digitalization and democracy relate. Each of the chapters deals with more or less contingent situations and raises further and deeper - including empirical - questions about the role digitalization can have for the state of democracy, however understood. What a volume like this can do, however, is to provide concrete illustrations of how digitalization can be beneficial with an eye to democracy, and where it can go wrong. By doing so, we hope to contribute to a better understanding of the challenges. The reader can subsequently translate this to her or his own situation or environment, linking the personal reading to specific democratic processes, the level and type of digital activity, a

8 J Bohman, 'From Demos to Demoi: Democracy across Borders' (2005) 18 Ratio Juris 301.

9 This chimes with what WB Gallie described more than 60 years ago as 'essentially contested concepts'. These are concepts 'the proper use of which inevitably involves endless disputes about their proper uses on the part of their users'. The crux of such concepts is that their meaning is a veritable and valueladen theatre of operations. In other words, the users of such a concept adhere to competing views of its proper use or interpretation. WB Gallie, 'Essentially Contested Concepts' [1956] Proceedings of the Aristotelian Society 167, reprinted in WB Gallie, Philosophy and the Historical Understanding (London, Chatto and Windus 1964). 
country's legal culture, or its tradition as regards the role of the state and other actors in law making, etc.

\section{THE LENS OF DIGITALIZATION}

In this volume digitalization is understood as the way in which 'many domains of social life are restructured around digital communication and media infrastructures' or the way in which these media ${ }^{10}$ 'structure, shape, and influence the contemporary world'. ${ }^{11}$ If put on a continuum, three dominant positions on the role of digitalization can be distinguished.

At one end of the spectrum is instrumentalism, by which technology is regarded as a value-free and neutral tool in the hands of those who can use it for either good or evil. Technological applications are from this point of view the neutral bearers of the ideas and aims of their designers and users. Online tools, for example, can thus offer an excellent solution in strengthening the legitimacy of politicians and policy makers. If the outcome is disappointing, the users are to blame, not the technology. Although the notion of technology as a neutral instrument has lost popularity in academic circles in recent times, it is often still very much alive in national and international policy making and public debate.

At the other end of the spectrum is what is called technological determinism. In this view, technology and digitalization is depicted as an irresistible force that follows its own logic and has a major impact on the way work, the economy and society as a whole are organized. ${ }^{12}$ Technological determinism can take both an optimistic and a pessimistic view of technology. The optimists believe that everything technologically possible will come to pass and will benefit society. The pessimists agree that everything technologically possible will come to pass but believe that society will be 'overwhelmed' and 'suffer a loss of autonomy and solidarity'. They fear a world driven by technological rationalism, with little regard for the human dimension. ${ }^{13}$

10 Such as data and databases, computer programs and software, social media, digital visualization and video, online and mobile games and applications, web pages and websites, location-based services, social media, e-books, etc.

11 Brennen and Kreiss (n 1).

12 R Williams and D Edge, 'The Social Shaping of Technology', in WH Dutton (ed.), Information and Communication Technologies. Visions and Realities (Oxford, Oxford University Press 1996) 55.

13 J Ellul, La systeme technician (Paris, Calmann-Levy, 1977); G Anders, Die Antiquiertheit des Menschen. Über die Seele im Zeitalter der zweiten industriellen Revolution (Munich, CH Beck 1980). 
The middle ground between the two consists of a dense multidisciplinary field that is more constructivist and dynamic in approach. Proponents of this middle ground regard technology as both a cause and an effect of societal change. ${ }^{14}$ The form that an application ultimately takes is then the result of various choices and the outcome of existing social, economic and technological relationships. ${ }^{15}$ In tune with this last position, in this volume digital tools are viewed as part of a dynamic interplay of multiple processes, interests and actors. Of key importance is the role of actors, ${ }^{16}$ because the way in which digital tools are used in democratic processes depends on the interests, ability to influence, views, knowledge and skills, expectations, and values of the relevant actors (citizens, national and international governments, NGOs and other users), as well as on the technical possibilities and impossibilities of the specific digital tools involved. ${ }^{17}$

The role of the government, being one of these actors, is particularly interesting in that it has to navigate between possibly contrasting capacities and responsibilities in this regard. Using, for example, new tools and information flows innovatively in its own deployment and for legitimate aims - improving government policies for, e.g., crime prevention, fraud detection, fair taxation and the performance of all kinds of daily services $^{18}$ - must be weighed against its duty to protect citizens against the effects of these tools and flows, prominent among them being the infringement of privacy. The same applies to the deployment by public institutions of online tools to enhance and facilitate democracy. As shown in the chapter by Colette Cuijpers, digitalization on the one hand increases democratic possibilities - openness adding to the legitimacy and accountability of government - while on the other hand may create a situation where, by means of information and communication technologies (ICTs), human rights can be trampled.

In addition to these roles, government is to a certain extent also responsible for the way society as a whole functions in using technology, and

\footnotetext{
14 Williams and Edge (n 12) 55.

15 W Bijker and J Law (eds), Shaping Technology/Building Society. Studies in Sociotechnical Change (Cambridge, MA, MIT Press 1992).

16 An actor is something or someone who makes a difference in a relationship. B Latour, Reassembling the Social. An Introduction to Actor-Network-Theory (Oxford, Oxford University Press 2005).

17 A Stirling, "Opening Up" and "Closing Down"” (2008) 33(2) Science, Technology and Human Values 262.

18 This is even more pressing since a government can be a monopolist in its use of technology: citizens cannot always decide to go to 'another government' in the event they prefer another level of service.
} 
thus how businesses, health care, etc. make use of digital opportunities. ${ }^{19}$ Illustrative here is the advent of big data, in particular where personal data are gathered and processed concerning (potential) behaviour of individuals or groups of individuals in order to influence their behaviour (in their capacity as, e.g., consumers, road users, patients, taxpayers and voters). Unsurprisingly then, an important theme that is often discussed in relation to big data involves concerns over privacy, increasing inequality, the risk of stigmatization and possible discrimination (whether this is deliberate or simply an unintended consequence). ${ }^{20}$

\section{THE LENS OF DEMOCRACY AND LAW: THE CHAPTERS IN THIS VOLUME}

Every view on democracy ultimately seems to derive from an original exemplar. Although it is true that the contours of modern-day democracy are to a large extent a product of the eighteenth century, these contours themselves are the offshoot of the portrayal of democracy as it was first shaped by the Greeks in the fifth century BC and which reached its peak in Pericles' Athens. ${ }^{21}$ Possibly the most traditional notion underlying the concept is that of 'self-legislation' (Selbstgesetzgebung). In this sense, so the consensus appears to be, democracy is indeed primarily an Athenian invention. The classic Greek city was governed not by a body of people's representatives but by all 'citizens', ${ }^{22}$ who constituted the People's

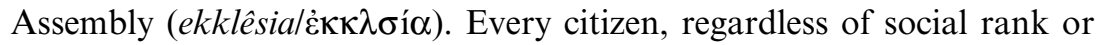

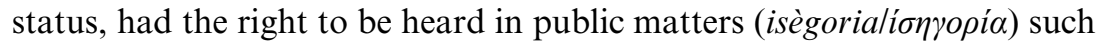
as foreign policy, war and peace, and the election of senior city officials and legislation. In this way, these citizens laid down the law by which they themselves would be governed (and which they themselves also had to

19 JEJ Prins, D Broeders, H Griffioen, A Keizer and E Keymolen, iGovernment (Amsterdam, Amsterdam University Press 2011).

20 L Moerel and JEJ Prins, Privacy for Homo Digitalis. Proposal for a New Testing Framework for Data Protection in the Light of Big Data and the Internet of Things (May 2016, SSRN Paper id=2784123) < http://papers.ssrn.com/sol3/papers. cfm?abstract_id52784123> accessed 19 August 2016.

21 On this, e.g., M Herman Hansen, The Athenian Democracy in the Age of Demosthenes. Structure, Principles, and Ideology (Oxford, Blackwell Publishers, 1991) and D Kagan, Pericles of Athens and the Birth of Democracy (New York, Simon \& Schuster 1991).

22 Excluding slaves, foreigners and women! The definition of a 'demos', or community, is, no matter how normatively objectionable from a contemporary point of view, an unavoidable socio-political feature of 'democracy'. 
implement). ${ }^{23}$ This line of thought ties in with the idea of popular sovereignty, a system of government that brooks no or very few intermediary bodies between the people and the norms that they define on behalf of and for the people.

The strength of this classic form of democracy is believed to lie in its potential to empower citizens to become experts through participation in public life. To the ancient Athenians a citizen was, to use Aristotle's

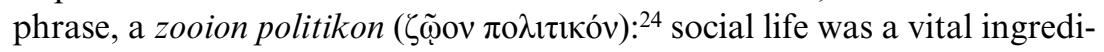
ent of existence and belonging to and living for one's polis the acme of being human. The state was thus not the outcome of a social contract freely concluded by individuals but the perfection of man's social nature; a natural necessity, orientated towards the public good. It is readily discernible that in this perception the distinction between the social (personal) and the political (or the public and the private realms), unlike in this day and age, converge to the point of becoming indistinguishable. In ancient Athens the political was social, and the social political.

\section{A. Participatory Democracy and Citizenship}

Intriguingly, it is the Athenian notion of democracy that today is often relied on, either explicitly or by implication, to remedy a number of 'fatigue symptoms' of current modes of representative democracy. This notion of democracy resembles what is today framed as a deliberative or participatory democracy. ${ }^{25}$ Opposed to more utilitarian or economically inspired conceptions of democracy - in which representative interest groups compete with each other on the political 'market' - this line of thought situates values like autonomy and equality in decision-making processes in pole position. The idea is to revive classic Athenian 'republican' ideas about public decision making, while at the same time keeping up with the attainments of a modern democratic political culture, which here refers to

23 All the same, some decisions were left to a policy preparation council of 500 citizens (the Boulè/Bovגí).

24 This connotes 'social creature' rather than, as is many times claimed, 'political animal'.

25 On this: S Benhabib, 'Toward a Deliberative Model of Democratic Legitimation', in S Benhabib (ed.), Democracy and Difference (Princeton, Princeton University Press 1996) 69: 'According to the deliberative model of democracy, it is a necessary condition for attaining legitimacy and rationality with regard to collective decision-making processes in a polity, that the institutions of this polity are so arranged that what is considered in the common interest of all results from processes of collective deliberation conducted rationally and fairly among free and equal individuals.' 
a culture where the protection of the values of personal freedom is prime, and in which equality - everyone deserves equal respect as autonomous and thus free persons - is the most genuine form of morality, which should be protected by the constitution and its concomitant rules and legislation. ${ }^{26}$

For a participatory democracy to flourish it is considered to depend on what is known as civic culture or civil society. An active perspective on democracy

envisions politics not as a way of life but as a way of living - as, namely, the way that human beings with variable but malleable natures and with competing but overlapping interests can contrive to live together communally not only to their mutual advantage but also to the advantage of their mutuality. ${ }^{27}$

Illustrative for participatory democracy and citizenship are online platforms that facilitate transparency of government information and help empower citizen participation in policy making. Several contributions in this volume also testify that civic participation can be facilitated by digital means. In their chapter on digital support in US rulemaking, Farina, Blake, Newhart and Nam show that so-called 'e-rulemaking' can facilitate transparency of government information and help empower citizen participation in policymaking. The specific context of US rulemaking illuminates both the challenges and the opportunities of using technology to enable a wider range of citizens to experience direct participation in complex policymaking processes. The authors conclude that it is probably not realistic to expect that individuals, small businesses, local and tribal governments and non-governmental organizations will ever be able to compete on equal terms in the policymaking arena with organized corporate, trade and professional interests. What is possible, however, is to make the participatory playing field less unequal in terms of, for example, awareness, reducing the overload of information, and motivation to engage. But this requires that someone invests the resources in alerting affected groups and makes relevant policy information understandable, thus, in short, honing participatory literacy skills. The potential can, however, only be realized if those who design and deploy participation tools make thoughtful choices that align technological affordances with

26 This morality is from this point of view not just some personal idea about justice, but derives from historical, social and political events, is institutionalized in documents, judicial decisions and institutions, and also stems from ideas about society as a 'fair system of cooperation' (to use Rawls's terminology).

27 B Barber, Strong Democracy. Participatory Politics for a New Age (Berkeley: University of California Press 1984) 118. 
the nature of the specific democratic process involved and the needs of the citizens whose participation is sought.

In his chapter on Dutch and Belgian manifestations of digital democracy, van Aeken also elaborates on the potential of online tools in facilitating the deliberative or participatory model of democracy. To gain a better insight into the potential contribution of online tools to further democracy van Aeken developed an analytical framework which he applies to two representative cases: a Belgian platform for citizen engagement in the city (CitizenLab) and the Dutch initiative of Internet Consultation for legislation. Van Aeken concludes that in particular 'the "social, local and mobile" features of digital democracy technologies may determine its success with regard to a deepening of democracy in the intricate context of transforming legal-political realities'. He is, however, less optimistic about the potential of internet consultation. Whereas this tool theoretically enhances the inclusive character of legislation, empirical findings show there are some key issues that prevent a true 'deepening of democracy':

the practical exclusion of citizens with lower educational baggage, the overrepresentation of well-organized interest groups, and the inclination of the ministries to take up a defensive position in supplied documents and feedback at the expense of a more reflexive attitude. Technological capabilities may provide partial solutions (such as increasing engagement through the use of social networks and digital media) but the prevailing factor in the success of this particular digital democracy manifestation is the attitude of the executive and administrative actors.

Another chapter illustrative of the role of online tools in facilitating participatory democracy and citizenship is that of Gylfason and Meuwese. Their discussion of the extensive use of digital tools in drafting the new constitution of Iceland - 'the world's first crowdsourced constitution Bill' - reveals that the use of such tools resulted in a feeling of ownership encouraged by the open invitation to the public. It helped create the sentiment that this was indeed a constitutional Bill for the people and drafted by the people. According to the authors, this feeling of ownership may explain the strong support for the Bill in the 2012 referendum. What was also seen as a benefit of the experiment was the clear message that special interest groups were not being offered special treatment, thus strengthening the feeling of popular ownership. The Icelandic initiative is particularly interesting because not just Icelandic citizens, but even the world at large, could join the deliberations. Although the foreign contributions received were few compared with local ones, their input was considered valuable. Given comments came from people from all over the world, many felt that such a foreign involvement enriched the process. It broadened the debate 
to issues beyond the programmatic radar of political parties, thus putting the onus on the political establishment to defend the status quo with substantive arguments. Crucial, however, is the possibility to 'harness the collective intelligence of the people through scaling-up, using digital tools in combination with statistical sampling techniques to ensure that the input considered by the drafters reflects the much larger input received'. Overall, Gylfason and Meuwese are positive about the experiment in Iceland and recognize that 'this very dynamic makes trumping substance by process an attractive option for incumbent political representatives'.

The Iceland experiment triggers an exploration of the potentials of the internet as an instrument of global governance. Is a genuinely global public sphere, one allowing for a political discourse among people across borders and continents, possible via the internet? It is this challenging question that is addressed by Pernice in his chapter. In conceptualizing a global public sphere in terms of multilevel constitutionalism (placing the individual and not states at the centre of the inquiry), Pernice is positive about the potential advantages of information technologies as a means of promoting democratic rule making at the global level. As the author shows, the internet is itself a clear example of the need for and success of legitimate global regulatory processes, 'producing norms that are binding upon all public authorities and directly applicable to undertakings and private persons'. Pernice stresses that self-rule of the global citizen through online tools should be seen as additional and complementary to the existing instruments. Online tools could indeed compensate for a range of democracy and efficiency deficits at the local, regional, national or even the supranational level. However, in order to do so a key challenge now is to develop institutional settings to harness the virtues of the internet in order to make democracy and constitutionalism for the benefit of the individual operational in the global context, all while not putting at risk the 'democratic functioning of political systems at other levels'.

Also optimistic is Zhao: the democratically beneficial effects are also the main focus in his chapter on the role of digital media in - especially state-critical - political communication. Since China entered the Digital Age there has been, Zhao notes, slow but substantial and irreversible progress towards democracy and a rule-of-law culture, which has been largely unnoticed by the broader public. Paradoxically, this development is the result of state oppression of digital means: the result is substantial progress, ranging from enlarged online free speech to more freedom of information, to increasing democracy awareness, to improved political transparency and accountability, to a popular participatory culture among Chinese citizens, and, most importantly, to the rise of young generations of netizens. 
At the same time, there is nothing in the operational logic or inner workings of the new media itself that would promote the idea that everyday life problems can be discussed in a truly political sphere. One of the most important features of democracy - free communication - can even pose a most serious threat to democracy and therefore to freedom itself. Bayamlıoglu, in his chapter, is highly critical of the atomization of free speech and of the filter bubbles caging users in their own personalized cognitive cubicle: both are the reflections and also reinforcing factors of the transformation observed in the current media landscape - namely, the shift to a revenue model of free speech. This suppresses and neglects the communication channels through which freedom of speech is exercised in a more collective and unified manner. The danger is the eradication of solidarity and cohesion necessary for organized political action. Since political discussions on social media are mostly single-issue campaigns which emerge in a reactive fashion, the loss of collective speech also signifies a certain degree of disintegration of the organizational texture of modern society - e.g., trade unions, political parties, newspapers and universities. In any event, when communication becomes an end in itself, it creates a hyper-plurality that can obstruct any systemic political criticism. The result might well be a risk for the solidarity and cohesion necessary for organized political action.

And although more optimistic than pessimistic about the democracy potential of digitalization, Zhao also draws attention to the escalation of cyber stalking and violence in this regard, which may lead to a negative view of cyber life among many Chinese who are unfortunately the victims. He also points out that those Chinese netizens who express their own ideas and actively participate in public events are mostly younger generations, the upper social classes and those who are well educated. Usually people who are poor, less educated and older are represented to a lesser extent because of the difficulties in accessing the internet and having their voice heard online.

Warnings can also be read in the chapter by Cuijpers. She shows that online tools can lose their value for democracy by being used to strengthen biased views. In particular the opaqueness of certain online communication and decision-making processes creates room for manipulation. This then could result in a lack of control or a shift of control to entities with less, or even no, democratic legitimization. Governments are thus called upon not to lose control to commercial interests of tech firms (explicitly or implicitly) determined to run politics and thus democracy. ${ }^{28} \mathrm{~A}$ similar risk

28 M Moore, Tech Giants and Civic Power (London, The Policy Institute at King's College 2015); G Moss and S Coleman, 'Deliberative Manoeuvres in the 
is that customized content, based on opaque profiling, divides society into groups of like-minded individuals. These groups are constantly shown content that is selected based on their previous activities, which shapes their personality, limits the sources of information they are exposed to and thus is a risk for a democratic society and freedom of speech (the so-called 'filter bubble ${ }^{29}$ ). We will briefly return to this in Section IV below.

Banerjee, in his chapter, approaches free speech from a different angle and criticizes the too formalistic view on censorship that the Indian Supreme Court adopted in a landmark judgment in 2015 (Singhal). This case struck down section 66A of the Indian Information Technology (IT) Act 2000, which provides for punishment, with a maximum of three years' jail and a fine, for sending 'offensive' messages through a computer or any other communication device such as a mobile phone or tablet. The Court found that section 66A was vague and arbitrary, and also disproportionately invaded the right to free speech. The judgment clearly increased the scope of the right to free expression, because liberty of thought and expression was believed to be a value of crucial significance under the constitutional scheme. Banerjee draws attention to the fact that free speech on the internet is nevertheless still in danger in India because censorship can also emanate from non-state actors and through intimidation. Indeed, the impact of Singhal may well be to transform the nature of internet censorship, through the use of intimidation and threats, perhaps in more subtle ways than usual. A broad view on censorship, paying attention to the social and political circumstances that can stifle dissent, is, according to Banerjee, necessary for countries like India, where the rule of law is still weakly developed.

\section{B. Representation}

The Athenian concept of democracy discussed earlier mainly involved direct democracy. Its corollary is representative democracy. In such a system of government, majority-based political decisions are taken by those members of the public who have been elected by their fellow citizens to act on their behalf. Today, representation is mostly perceived as a check on passing fads, as a buffer against populist or tyrannical majorities or as a form of necessary division of labour: the people are excused from

Digital Darkness: e-Democracy Policy in the UK' (2015) 16(3) The British Journal of Politics \& International Relations 410.

29 E Pariser, The Filter Bubble: What the Internet is Hiding from You (London, Penguin 2011). 
continuous involvement in politics (a futile task for non-specialists) and politicians are given the time and means to specialize in it. Representation appears typical of a modern democracy, and elections and voting processes are crucial to it.

But as Weill makes clear in her chapter, embracing digital means in elections may be a risky endeavour for democracies. The assumption that digital election processes can be reliable may not accord with reality, given also that the incentives of saboteurs - both insiders and outsiders to the process - to sway electoral results are immeasurable. To be constitutional, electronic voting must, according to Weill, meet proportionality requirements, which requires that the transfer to e-voting must be authorized by statute; that it should be done for a proper purpose; that the means chosen should be rationally linked to achieving the statute's goals; that the constitutional infringements must be designed to be as limited as possible for achieving the statute's goals; and, most importantly, that the advantages of e-voting should outweigh their costs in terms of infringement of constitutional rights. Moreover, it is not enough that the elections meet these requirements de facto. Rather voters must also believe that these requirements are actually met. Weill argues that the stronger the democratic culture of a country - including a media 'watchdog' and healthy competition among political candidates and parties - the easier it will be for that country to experiment with e-voting.

At the same time, the face of representation might well be changing drastically. In his 2009 book on the history of democracy, John Keane notes the inception of a new type of democracy, which complements, amends and adjusts representative democracy by means of a growing number of organizations and activities that critically follow the performance of official state institutions, but also add to its legitimacy. ${ }^{30}$ Keane shows a prodigious variety of forms of what he has framed as "monitory democracy': citizens' participation in municipal budgets, think tanks, consensus conferences, democracy cafés, deliberative opinion polls, and social forums, etc. One could of course say that most of these manifestations are expressions of liberalism (self-ordering civil society) rather than of democracy as classically experienced in the political-cultural dimension. By relabeling instruments of liberalism as 'monitory democracy' we open the way to the abandonment of democracy's anchor in classic

30 J Keane, The Life and Death of Democracy (London, Simon and Schuster 2009). Keane believes that the old maxim of representative democracy - one person, one vote, one representative - is making way for a new maxim: 'One person, many interests, many voices, multiple votes, multiple representatives' (p. 691). 
demos-representation. As Rosina, Moncau and Lazzari show in their chapter, the internet has indeed become an important instrument in promoting an open and robust public sphere, enabling people to apply pressure and claim specific changes or rights. However, their analysis also indicates that the use of ICTs alone may just not be enough to achieve concrete institutional changes. The concrete examples brought forward in their chapter provide empirical evidence of Brazilian experiences. They conclude that the goals of civil society groups are better achieved when, next to ICT, they are able to gain space and attention of more traditional media. It is the association of strategies and tools (traditional and innovative) that makes the difference for democracy at the end of the day.

That the success or failure of online tools is very much related to strategy is also something that becomes clear from the chapter by Kong, Luka, Cudmore and Dumas in discussing the experiences from the McGill Online Design Studio (MODS), aimed at increasing opportunities for meaningful citizen deliberation about urban design. Such deliberation implies much more than merely launching an online platform. To ensure the success of digitally mediated deliberative work, creative and aggressive public recruitment is needed to ensure sustained participation. Efforts must be made to establish personal relationships between project staff and (potential) participants if the latter group is to feel confident about getting involved. The authors also demonstrate that particular attention must be paid to how online forums are designed in order to ensure that they encourage effective deliberation. This then goes back to our earlier observation (Section II) that technology is not a neutral instrument but is both a cause and an effect of societal change. Clearly, the MODS experience testifies that digital tools must be viewed as part of a dynamic interplay of multiple processes, interests and actors.

\section{Nation-state, Globalization and the Role of 'Law'}

As was noted earlier, democracy saw the light of day in the context of the city-state. It later flourished in what was called the nation-state: ${ }^{31}$

31 The rise of the nation-state is of course a complex, dialectic development. Usually one is referred to the Peace of Westphalia (1648) as the starting point, although the concept of the state as such developed from the thirteenth century onwards. For nuance and details see $\mathrm{M}$ van Creveld, The Rise and Decline of the State (Cambridge, Cambridge University Press 1999) and H Spruyt, The Sovereign State and its Competitors: An Analysis of Systems Change (Princeton, Princeton University Press 1994). On the term state and its use, see 
democracy, community and a specific territory indeed share a longstanding and close connection. The nature of the demos, the political community, the definition of citizenship, notions of self-rule, representation, accountability and transparency, has for a long time been associated almost solely with the institutions of the nation-state. And there is a good measure of interaction because over time the increasing authority of the nation-state has reinforced the bond between democracy and territory.

Even so, the national perspective is waning, at least functionally. ${ }^{32}$ Increasingly, power rests not with the national government, its institutions and its citizens, but with multinational corporations, which bring their influence to bear on industries and the international economy. ${ }^{33}$ Consequently, the effectiveness of national administration declines. In a global system of intensifying interdependence, social problems rarely respect territorial sovereignty. All this raises the question of what meaning is left to a number of major official institutions of the democratic political system which are mostly developed in nation-states, such as an elected parliament. Will it suffice, politico-culturally, to merely create a sense of democratic self-government in a historically recognizable fashion? The question, more pressing than ever before, is how democracy can be translated to a world without borders. What meaning, in the context of digitalization, can democracy retain if it is severed from the community in which it is to function?

All this might also have implications for our notion of what it means to deal with 'law' and for what it means to create 'law' (or regulation) in a democratic manner, e.g., in line with 'rule of law' guarantees and safeguards. In any case, the Western idea of law as 'state law' (or state legality) is a concept that just partly catches the normative reality within which law and norms function. By considering state law to be the standard, one gives non-Western or non-standard forms of normativity a place in the shadows. However well intended the ambitions might be, the researcher thus becomes guilty of conceptual colonization. There is no single legal norm that can be encapsulated in a coherent and neatly hierarchical system; the reality is too complex for that, and fragmentation

A Guéry, 'The State. The Tool of Common Good', in P Nora (ed.), Rethinking France. Les lieux de mémoire (vol. I, Chicago, University of Chicago Press 2001) 1.

32 Although it seems to persist within what might be called a political-cultural dimension.

33 Barber astutely observes that while democracies are interested in markets the reverse is not necessarily true. B Barber, Jihad vs. McWorld (New York, Times Books 1995) 243. 
and polycentricity are key for analysis. Therefore we might well need the language of hybridity to catch normativity and regulation. ${ }^{34}$

The complex relation between globalization (or the interaction between cross-boundary orders), democracy and regulation (governance) is also the focus of at least three of the chapters in this volume. The Lisbon Treaty (Treaty on European Union - TEU) introduced the citizens' initiative as a new right granted to the citizens of the European Union. Within the new title on 'Provisions on Democratic principles', Article 11.4 of the TEU states:

Not less than one million citizens who are nationals of a significant number of Member States may take the initiative of inviting the European Commission, within the framework of its powers, to submit any appropriate proposal on matters where citizens consider that a legal act of the Union is required for the purpose of implementing the Treaties....

The question addressed by Garot is to what extent the European citizens' initiative might foster (direct) democracy in the European (if not global) sphere, thanks particularly to the internet. She concludes in her chapter that most of the European citizens' initiatives undertaken have been disappointing, including with regard to finding support for these initiatives through the internet. Even data on successful initiatives show that for diverse reasons the internet did not play a decisive role, either in the campaigning, the collection of support and signatures or in the promotion of a cross-border effect. The transnational effect, and the outcome of the initiative, will, according to Garot, ultimately depend on the implementation and organizational structure of the different Member States.

From the perspective of governance, what is specific to the internet, Zingales and Radu note in their chapter, is the absence of a treaty signed by sovereign states to regulate key aspects of the network or activities conducted online. While an agreement was reached to assign to an international organization specific technical matters such as the international radio frequencies spectrum, satellite orbits and global telecommunication standards, a wide range of issues have been left either unaddressed at the international level, or are only 'informally' regulated through mechanisms of 'soft law' that leave ample room for experimentation (and continuous reform) at the national or regional level. So how can a smooth, peaceful and efficient coordination of the network of networks

34 On this, see also the work of Seán Patrick Donlan, e.g., 'Things Being Various: Normativity, Legality, State Legality', in M Adams and D Heirbaut (eds), The Method and Culture of Comparative Law (Oxford, Hart Publishing 2014). 
be ensured in the absence of an overarching international treaty? The near-absence of transnational treaties for regulating internet communication is part of a broader paradigm shift towards the governance of public resources, which implies a reconsideration of sovereignty and of the extent to which states act as governors. In this context, multistakeholder participation, as Zingales and Radu point out, has emerged as the mode of governance most typically associated with the governance of the cyberspace. It is premised on the transnational engagement of different actors in decision-making processes, including governments, civil society and the private sector. And although no single formula of multistakeholder participation has prevailed so far, its various embodiments are closely linked to the ideals of deliberative democracy, aiming to strike a balance between process fairness (in particular equal footing), political equity (power and influence) and deliberation. A key element here is the use of procedures and guiding norms for interaction in order to ensure that the viewpoints articulated are taken into account and debated in a constructive manner, while allowing for input and feedback from other actors. Many questions, however, still stand out: institutionalization of multistakeholderism, which procedures to use when making decisions, whether multistakeholderism is a form of decision making or a form of representation, to whom stakeholders are precisely accountable, what their legitimacy is, and how inclusive it can be given that sometimes low levels of access to and use of ICT do not allow for meaningful engagement in global governance debates.

Finally, in his chapter, Pernice, too, notes that global governance does not function through traditional democratic legislative procedures but increasingly follows the method of 'multistakeholderism'. In his view, direct-deliberative e-democracy can be extended to encompass the global dimension as an increasingly relevant element of self-government. However, it is questionable whether, at this moment in history, deliberation and consent in open, public and inclusive multistakeholder processes would suffice to compensate for a lack of parliamentary consent at the national level; the system would also, for example, need some mechanism to oversee compliance and to settle disputes, all the while remaining sensitive to the protection of fundamental rights. Monitoring and review processes will also play a crucial role. Not only will the new constitutional setting require ongoing evaluation, but so will the standards and rules established in the proposed system of multistakeholder-driven global norm setting, based upon the internet and the experiences with internet governance. Nevertheless, according to Pernice, now is the time for the development of a type of citizenship focused on e-democracy and multilevel constitutionalism. 


\section{SOME FURTHER THOUGHTS: A NETWORKED APPROACH}

Pagallo, in his chapter, points out that many of the current troubles with democratic processes are often discussed and presented as if they were new. Building on Norberto Bobbio's work, ${ }^{35}$ he explores the 'six broken promises of democracy', which cast light on many crucial aspects of current discussions on digital democracy. They deal with respect for individual sovereignty, the primacy of political representation, the defeat of oligarchies, the increase of spaces for self-government, education of citizens, and transparency of governments. From this it follows, Pagallo writes, that many democratic problems of current digital trends are as old as democratic theory itself. We can nevertheless also trace new democratic challenges with regard to digitalization. These challenges mainly have to do with the ingredients of the rule of law: to what extent can values such as equality, accessibility of the law, and fair procedures still be guaranteed? For example, phenomena such as spamming, phishing, viruses and cyberattacks have increased over recent years despite harsh national laws such as the US Anti-spam Act of 2003. This has obliged legislators and policymakers to develop more sophisticated ways to address matters of legal enforcement through the mechanisms of design, codes, and architectures, which challenge the canonical idea of the law as a certain set of rules enforced through the threat of physical sanctions. Pagallo concludes with a threefold proposal - call it a 'digital ethic' - to tackle these challenges: (a) any kind of impoverishment of being in the info-sphere ought not to be caused; (b) informational entropy ought also to be prevented or removed; and (c) old and new challenges of digital democracy should be tackled with a margin of tolerance.

Nevertheless, differences in political, cultural and democracy systems make generalizations about the relation between digitalization and democracy difficult (and Pagallo of course acknowledges this). It could well be, for example, that satisfaction with the political regime plays a role in the alleged effects of new online tools that facilitate political participation. The perceived benefits of online tools could thus appear marginal in countries with stable democracies - at least for the majority of their citizens - and not to outweigh the time and energy involved. This, in contrast, could be completely different for those living in countries with less wellfunctioning democracies. Another factor making it difficult to draw firm

35 N Bobbio, The Future of Democracy (Minnesota, University of Minnesota Press 2014; originally published in 1984). 
conclusions on the democratic potential of digitalization is that systematic studies that have sought to examine the degree and nature of the changes in participation and representation are scant. The true impact on democracy of online tools and their lowered threshold for citizen participation is in any case difficult to measure. And even if we were in a position to more or less measure it, such impact can simultaneously be positive and negative depending on the value at stake (e.g., open government fostering transparency on the one hand and privacy on the other hand). As Cuijpers rightly argues in her chapter, positive or negative effects depend on the way digitalization is employed by the different stakeholders. She therefore concludes that

... instead of trying to identify the impact of digitalization on democracy from an overarching perspective, the debate should first focus on better understanding the impact of digitalization on the pillars, values and interests underpinning democracy, taking into consideration the difficult interplay between the different stakeholders and technology as a separate, non-neutral, actor.

Also, the political configurations are changing constantly, not only because of regime change, changes in politics and thus with regard to 'room for democracy', but also because technological innovation as such has its effect on democratic processes. In today's society, where data sharing is rapidly becoming the rule rather than the exception, the scope and nature of intelligent data usage will certainly impact democracy. And in doing so, it does not follow a grand design but, as argued in Section II, is shaped through a dynamic interplay of multiple processes, interests and actors. As said, of key importance then is the role of actors. For the way in which digital tools are used in democratic processes depends on the ability to influence views, knowledge and skills, expectations, and values of the actors as well as on the technical possibilities and impossibilities. In looking at recent developments and in particular the advent of big data, it is therefore crucial to acknowledge that the 'democracy playing field' is changing in that new interactions and interdependent actors have entered the scene. Today it is by no means only government and citizens who play their role in shaping democracy and democratic processes. High tech firms also make their contribution to the dynamics of democracy. Illustrative of the power of the new actors is not only the suggested role Facebook played in the 2016 US presidential election but also an earlier, highly controversial tool it developed, the 'voter megaphone'. Using massive amounts of data, Facebook's intelligent algorithms categorize citizens and manipulate their voting behaviour in hidden ways. The tool provides users an easy way to share with their friends the fact that they are voting. Studies 
showed that Facebook's nudging indeed increased voter turnout. ${ }^{36}$ In 2014 Facebook conducted a successful test run in the Indian national elections and made the tool available to Brazilian voters in their 2014 elections. The company subsequently announced 'that it would be putting the tool on the pages of users in all the major democracies holding national elections this year and that it would also deploy the tool for the European Union vote' ${ }^{37}$ And Facebook nudges in other manners as well. For example, it has tested whether changes in the news feed seen by its users - but without their being alerted to it - affect their level of interest in politics and their likelihood of voting.

Of course, democracy has always been shaped and adapted in response to new developments and dynamics, and the current era is no exception. But it is crucial that this shaping works out in a more or less balanced manner, in particular given technology cannot be regarded as value free and multiple actors all apply the new tools according to their own interests. Innovation in tools that facilitate democracy is therefore always accompanied by uncertainty. Given this and combined with the variety of perspectives that unfold in this volume's chapters, we feel that a distributed approach appears necessary. ${ }^{38}$ Division and mixture are needed in order to create as many checks and balances on every actor's (public, private, civil) behaviour. Democratic states might well try to organize their interaction with the developments through what is called a networked approach, suitable for the fracture, fluidity and polycentricity that emerges from most of the chapters in this volume. But given that ambition, it becomes a challenge to envision who then is going to shake the hand of whom in reaching any subsequent decision. Put differently, which actors and institutions should participate in the process of enriching democratic societies by means of online tools? Some actors might be effective (so-called 'Anonymous', hacktivists or high tech firms like Facebook) but they seem to lack legitimacy in what they do. Others might be considered to have legitimacy (sovereign states), but sometimes lack the necessary digital awareness, actual power and influence in the online world. Does this imply that we need to get representation of certain actors in ways that

36 ML Sifry, 'Facebook wants you to vote on Tuesday. Here's how it messed with your feed in 2012' < http://www.motherjones.com/politics/2014/10/can-vot ing-facebook-button-improve-voter-turnout $>$ accessed 19 August 2016.

37 Ibid.

38 RJ Deibert, Black Code: Inside the Battle for Cyberspace (New York, Random House 2013); WH Dutton, 'The Fifth Estate Emerging Through the Network of Networks' (2009) 27(1) Prometheus $1<$ http://papers.ssrn.com/sol3/papers.cfm?abs tract_id51167502> accessed 19 August 2016. 
better reflect the powers in the digital world? A networked (distributed) approach in reacting to digital movements and developments might well be illustrative of the evolution of a 'law' beyond the legal orders of national states and also beyond the international law frameworks that are derived from the will of sovereign states. So while acknowledging that the effects of digitalization on democracy are not easy to assess and address, we can nevertheless explore the responses to them. This volume therefore also attempts to identify the specific law and public policy responses in different democratic traditions. In engaging with these responses and reflecting on their - cross-border - effects, we not only hope to contribute to a better understanding of the challenges we face, we also hope to give concrete substance to these responses.

Finally, the journey undertaken in this volume started with a reflection on a subject of common fascination for many of its contributors. On the one hand we witness digital technology opening the door to a greater role for the public, we see companies such as Facebook and Google that appear to have more regulatory power in a cross-border information market than nation-states, and we notice extraterritorial implications of data-transfer that are determined by completely new factors, among them normative standards implemented in technological code. ${ }^{39}$ At the same time, digital tools put pressure on the traditional ordering of democratic processes. This volume intends to explore the challenges that digitalization poses to democracy. In doing so, the different chapters also contribute to the broader discussion on the relationship between international, national and sub-national norms, institutions and actors in a global world. This being a world in which digital technologies have become part of the very fabric of interaction and communication.

39 L Lessig, Code and Other Laws of Cyberspace (New York, Basic Books 1999). 
Maurice Adams and Corien Prins - 9781785363962 Downloaded from PubFactory at 04/26/2023 05:18:36AM 